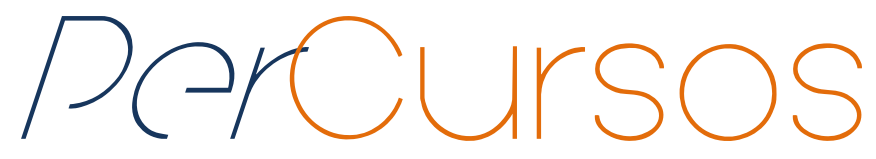

\title{
O protagonismo do PIBID no processo de letramento literário
}

\begin{abstract}
Resumo
Este texto objetiva trazer à luz duas propostas de sequências didáticas desenvolvidas em escolas da Educação Básica da rede pública do Paraná, planejadas com intuito de favorecer o letramento literário. $\mathrm{O}$ trabalho com o texto literário em sala de aula apresenta-se, muitas vezes, como um desafio para o professor de Língua Portuguesa do Ensino Médio. Além de se deparar com alunos pouco interessados nesse tipo de leitura, ainda enfrenta insegurança quanto à metodologia mais eficaz para que a atividade desenvolvida não se torne mera aula de história da literatura, mas sim que ofereça um ambiente que propicie a formação de leitores críticos e desperte o prazer pelo texto literário, tornando a leitura um hábito que favoreça o letramento literário. Considerando estes apontamentos, o PIBID-Letras Programa Institucional de Bolsa de Iniciação à Docência-CAPES, desenvolvido na Universidade Estadual do Norte do Paraná (UENP, campus de Cornélio Procópio), procura contribuir para o processo de letramento literário, buscando amparo teórico e metodológico nos estudos de Rildo Cosson (2009). Em 2015, duas escolas Estaduais no município de Cornélio Procópio, Paraná, foram contempladas com a intervenção do Programa. Para a efetivação da proposta de trabalho, foram realizados encontros semanais, tendo como pauta nas sessões, estudos voltados à formação para a prática docente, com ênfase no processo para o letramento literário, envolvendo professores e graduandos de Letras da UENP-CCP e professores da Educação Básica.
\end{abstract}

Palavras-chave: Formação Docente. PIBID. Letramento Literário. leda Maria Sorgi Pinhaz Elias

Mestre em Letras pela

Universidade Estadual de

Maringá - UEM. Professora da

rede estadual de ensino SEED/PR. Brasil

iedapinhaz@gmail.com

\section{Ana Paula Franco Nobile Brandileone}

Doutora em Letras pela Univ.

Estadual Paulista "Júlio de

Mesquita Filho" - Unesp/Assis.

Professora da Univ. Estadual do

Norte do Paraná - UENP.

Brasil

apnobile@uenp.edu.br

\section{Vanderléia da Silva Oliveira \\ Doutora em Letras pela Univ. \\ Estadual de Londrina - UEL. \\ Professora da Univ. Estadual do \\ Norte do Paraná - UENP. \\ Brasil \\ vances@uenp.edu.br}

\section{Para citar este artigo:}

ELIAS, Ieda Maria Sorgi Pinhaz; BRANDILEONE, Ana Paula Franco Nobile; OLIVEIRA, Vanderléia da Silva. O protagonismo do PIBID no processo de letramento literário. Revista PerCursos, Florianópolis, v. 18, n.38, p. 134 - 151, set./dez. 2017.

\section{DOI: $\mathbf{1 0 . 5 9 6 5 / 1 9 8 4 7 2 4 6 1 8 3 8 2 0 1 7 1 3 4}$ \\ http://dx.doi.org/10.5965/1984724618382017134}




\title{
PIBID's protagonism in the process of literacy literary
}

\begin{abstract}
This text aims to bring to light two proposals for didactic sequences developed in public elementary schools of Paraná that were planned to promote literary literacy. Working with the literary text in class is often a challenge to Portuguese high school teachers. Besides coming across students that are not interested in this type of reading, the teacher faces uncertainty about the most effective methodology so the activity performed do not become a mere literature history class. Rather, it is to offer an environment that is conducive to the formation of critical readers and awakes the pleasure for the literary text, making reading a habit conducive to literary literacy. Considering these notes, the PIBID-Letras - CAPES, developed at the State University of Northern Paraná (UENP, campus Cornélio Procópio), seeks to contribute to the literary literacy process, through theoretical and methodological support in studies by Rildo Cosson (2009). In 2015, two state schools in the city of Cornelio Procópio, Paraná, were included in the program intervention. Weekly meetings were held for the execution of the work proposal, with their agendas aimed to studies on training for teaching practice, with emphasis on the process for the literary literacy, involving teachers and graduate students of Letras UENP-CCP and Elementary school teachers.
\end{abstract}

Keywords: Teacher Formation. PIBID. Literacy Literary. 
É bastante frustrante para o professor de Língua Portuguesa constatar que, depois de pelo menos nove anos de bancos escolares, uma grande parcela dos alunos apresenta pouca experiência com a leitura de textos literários. Isso não quer dizer que os docentes dos anos anteriores não tenham destinado espaço para a leitura, mas sim, que as estratégias utilizadas para este trabalho podem não ter sido suficientes para formar leitores, especialmente literários. Dentre as funções exercidas pela escola, destaca-se a de formar leitores críticos e autônomos, capazes de articular a leitura de mundo à leitura do texto literário. De acordo com Cosson (2009, p. 23), “[...] o letramento literário é uma prática social e, como tal, responsabilidade da escola".

É fato que, muitas vezes, tanto o uso do livro didático quanto a formação inadequada do professor contribuem para que as aulas de literatura no Ensino Médio se resumam a aulas de história da literatura, em detrimento da experiência estética efetiva com o texto literário. Assim, prevalece o estudo sobre estilo de época e do autor, características da escola literária e biografia do autor. Com isso, a leitura efetiva e na íntegra da obra literária não acontece, seja pelo fato de o livro didático apresentar, não raro, fragmento de textos, ou por não haver uma biblioteca bem aparelhada no estabelecimento de ensino, com volumes suficientes de uma mesma obra para se trabalhar com uma turma, ou, ainda, pela falta de conhecimento do professor de estratégias de leitura que favoreçam o letramento literário. De acordo com Cosson (2009), para desenvolver o letramento literário, é necessário ir além da simples leitura do texto. Então, é indispensável o uso de mecanismos de interpretação e cabe à escola instrumentalizar os alunos para que façam uso deles.

Assim, optamos pela proposta metodológica de Cosson - Sequência Expandida -, em que o autor propõe as seguintes etapas para o desenvolvimento das atividades: motivação, introdução, leitura, intervalos, primeira interpretação, contextualizações, segunda interpretação, expansão. Esses passos serão pormenorizados ao longo deste texto, quando apresentaremos o desenvolvimento das sequências nas escolas contempladas com o projeto. ${ }^{1}$

As atividades do projeto podem ser verificadas no blog oficial em: <http://pibidportuguesuenp.blogspot.com.br/>. 
Cabe ressaltar que nas escolas públicas o acervo literário é quase que exclusivamente renovado por obras enviadas pelo governo Federal, por meio do PNBE Programa Nacional Biblioteca na Escola. Com intuito de promover a circulação dessas obras no espaço escolar - e ainda por entender que até esses livros comporem as estantes dos estabelecimentos públicos de educação eles passam por criteriosa seleção realizada por especialistas na área de literatura -, decidimos que os títulos lidos deveriam constar no acervo do PNBE. Após checar as expectativas de leitura dos alunos, as obras escolhidas para o desenvolvimento do trabalho foram: Dois Irmãos, de Milton Hatoum (2000), e A filha do escritor, de Gustavo Bernardo (2008). Tal escolha, além de trazer à tona obras e autores contemporâneos, extrapolando o circuito da periodização literária e dos cânones, ainda possibilitou que as escolas se articulassem junto ao NRE - Núcleo Regional de Educação, para que livros fossem remanejados entre as escolas do mesmo NRE. Com esse intercâmbio de obras entre as escolas, tem-se dupla contribuição: diminuição dos custos para a execução do projeto de leitura e possibilidade de troca dos materiais didáticos elaborados, entre os professores. A equipe diretiva dos colégios estaduais também se responsabilizara pela compra dos livros, garantindo que cada aluno das turmas envolvidas no projeto tivesse a obra sob seus cuidados durante 0 desenvolvimento das atividades.

\section{O PIBID e o letramento literário}

O PIBID vem se configurando como um programa que capacita tanto docentes em formação quanto aqueles que já estão no meio escolar, proporcionando a ambos, estudo, aperfeiçoamento e formação. O projeto visa à inserção dos licenciandos no cotidiano de escolas da rede pública de educação, a partir de atividades didático-pedagógicas significativas, sob a orientação de um docente da Universidade e supervisão de um professor do estabelecimento de ensino em que o projeto se desenvolve. Assim, o graduando tem a oportunidade de consolidar a articulação entre teoria e prática.

O Programa Institucional de Bolsa de Iniciação à Docência (PIBID/CAPES) se estabelece, ainda, como uma alternativa para o aprimoramento das práticas diárias do 
ensino de literatura nos colégios, uma vez que, pelos estudos realizados nos encontros, o professor da escola tem contato com textos teóricos, que apresentam novas técnicas e tendências de trabalho docente. Tal programa, que promove também a integração entre educação básica e superior devido à parceria entre os dois segmentos, concede bolsas tanto aos professores quanto aos alunos de licenciatura participantes. Isso contribui para que o grupo envolvido tenha condições de arcar com os custos que o projeto demanda.

Outro ponto a ser destacado é o vínculo que se cria entre os licenciandos e os alunos da escola, pois, como os trabalhos acontecem semanalmente, a experiência de docência difere muito das atividades de estágio, em que o graduando aparece como um "estranho no ninho alheio". Devido à frequência de convívio, o pibidiano tem mais conhecimento da turma, o que permite que a prática se torne ainda mais significativa.

Destacamos, também, que o termo letramento literário é entendido neste trabalho de acordo com a perspectiva dada por Cosson:

O letramento literário, conforme o concebemos, possui uma configuração especial. Pela própria condição de existência da escrita literária, [...] o processo de letramento que se faz via textos literários compreende não apenas uma dimensão diferenciada do uso social da escrita, mas também, e sobretudo, uma forma de assegurar seu efetivo domínio. (COSSON, 2009, p. 12)

Assim, pensamos o letramento literário como um processo permanente de transformação, uma construção e reconstrução inesgotável que se renova a cada leitura literária significativa, favorecendo a escolarização da literatura, que é a sua "apropriação" no espaço escolar, de modo a escolarizá-la e didatizá-la. Isso significa que a leitura da literatura feita na escola, seja no ensino fundamental ou no médio, situa-se num contexto específico e tem objetivos específicos. Este pensamento desencadeia outra reflexão: Por que estudar literatura? De acordo com Candido (1972), a literatura confirma a humanidade do homem. Afirma ainda que: 
As camadas profundas da nossa personalidade podem sofrer um bombardeio poderoso das obras que lemos e que atuam de maneira que não podemos avaliar. Talvez os contos populares, as historietas ilustradas, os romances policiais ou de capa-e-espada, as fitas de cinema, atuem tanto quanto a escola e a família na formação de uma criança e de um adolescente. (CANDIDO, 1972, p. 82)

Assim, seguindo a linha de raciocínio do autor citado, confirmamos a necessidade de a escola também responsabilizar-se pelo ensino de literatura. Zilberman compartilha das observações de Candido (1972), quando afirma que, "Se ler é pensar o pensamento de outros, é igualmente abandonar a própria segurança para ingressar em outros modos de ser, refletir e atuar. É, por fim, apreender não apenas a respeito do que se está lendo, mas, e principalmente, sobre si mesmo" (ZILBERMAN, 2001, p. 53). Para ratificar a responsabilidade da escola no ensino de literatura, nos remetemos mais uma vez a Cosson, que destaca: "Os livros, como os fatos, jamais falam por si mesmos. O que os fazem falar são os mecanismos de interpretação que usamos, e grande parte deles são aprendidos na escola" (2009, p. 26). Assim, entendemos o ambiente escolar como espaço privilegiado para estudo do texto literário.

\section{Duas experiências de sucesso}

Em 2015, dois colégios públicos foram selecionados para receber o PIBID-Letras. Em cada um deles havia uma professora da área, atuando como supervisora do trabalho de cinco graduandos cada, sob a coordenação geral do projeto e de uma docente colaboradora.

Como mencionado, para a sistematização dos passos da Sequência Expandida ocorreram encontros semanais durante o primeiro semestre de 2015, com estudos voltados tanto para a formação do leitor quanto para o amparo teórico/metodológico referente ao letramento literário. A partir desses encontros, foram elaboradas propostas de intervenção para cada uma das escolas e dos licenciandos. Sob a supervisão do professor da Educação Básica e coordenação dos professores da Universidade, os 
bolsistas experimentaram a prática em sala de aula, tendo este ambiente como laboratório para sua formação profissional.

As atividades que orientam o subprojeto PIBID estão voltadas para o Letramento Literário a partir dos pressupostos de Cosson (2009), no desenvolvimento de atividades sistematizadas de leitura literária, conforme anteriormente destacado. Para tanto, estas atividades articulam-se com os grandes eixos sobre os quais se pauta o ensino da Língua Portuguesa, conforme as Diretrizes Curriculares da Rede Pública de Educação Básica do Estado do Paraná (2008): leitura (literatura e demais esferas sociais), oralidade, escrita e análise linguística.

Para facilitar a nominação dos estabelecimentos de ensino, utilizaremos escola 1, que realizou a leitura da obra Dois Irmãos (2000), de Milton Hatoum, com uma turma de segundo ano do Ensino Médio, e escola 2, com a Filha do Escritor (2008), de Gustavo Bernardo, para o primeiro ano do Ensino Médio.

A motivação é a primeira etapa sugerida por Cosson (2009). Este é o momento de preparação do grupo para iniciar a leitura da obra. Na escola 1, os alunos foram levados a explorar a epígrafe da obra, retirada do poema “Liquidação", de Carlos Drummond de Andrade (1989):

\footnotetext{
A casa foi invadida com todas as lembranças todos os móveis todos os pesadelos todos os pecados cometidos ou em vias de cometer a casa foi vendida com seu bater de portas com seu vento encanado sua vista do mundo seus imponderáveis [...]
}

A partir da epígrafe e da maquete de uma casa produzida pelos pibidianos, os alunos foram levados a refletir sobre a imagem da casa e a sua representação, a fim de verificar a afinidade deles com cada cômodo e, em última instância, com a família. Em seguida, foram distribuídos pedaços de papel cartão para que cada aluno escrevesse um adjetivo ou substantivo que retratasse o sentimento em relação a um dos cômodos e, posteriormente, comentasse o que escreveu. A eles foi solicitado que colassem esses 
sentimentos nos cômodos da casa. Posteriormente, os alunos criaram um conflito familiar e o dramatizaram. Considerando que a primeira etapa da sequência expandida tem por objetivo levar os alunos a entrarem no universo da obra selecionada, a dinâmica acima explicitada encontra eco em Dois irmãos, uma vez que o eixo narrativo central aborda a intrincada e tensa relação entre Omar e Yaqub, gêmeos idênticos que, a partir da adolescência, são diferenciados fisicamente por causa de uma cicatriz no rosto de um deles, Yaqub.

Já na escola 2, como a esquizofrenia é um assunto constante no texto, ofertamos aos alunos a apreciação de trechos de vídeos com personagens famosos, esquizofrênicos, de telenovelas brasileiras. Com intuito de fomentar discussões, assistiram também a um vídeo de entrevista sobre esquizofrenia, com Ana Beatriz Barbosa no programa "Sem Censura". Em ambas as propostas, procurou-se estabelecer laços com a obra a ser lida, bem como despertar o interesse dos alunos pela história do livro.

O próximo passo é o da introdução, momento de apresentação do autor e da obra. Assim, em ambas as escolas, o procedimento foi semelhante. Como todos os alunos estavam com as obras em mãos, os bolsistas conduziram a exploração do objeto, destacando aspectos composicionais da capa, contracapa e orelha. A seguir, os alunos foram brevemente informados sobre a biografia dos autores. Na escola 1, os alunos foram apresentados ao escritor Milton Hatoum: biografia, obras publicadas, prêmios recebidos e estilo, sobretudo de Dois irmãos; para tanto foram elaborados alguns slides. $\mathrm{Na}$ escola 2, além da apresentação do autor do livro, os alunos também puderam conhecer um pouco sobre o escritor Machado de Assis, pois a obra lida se referencia com frequência a ele.

Ao final desse encontro, definimos os intervalos de leitura. Ficou acordado que as obras seriam lidas em três intervalos, com período de 7 dias para a leitura de cada trecho definido. A leitura foi realizada extraclasse e foram realizadas, a cada intervalo, atividades para averiguação do trecho lido. Também na escola 1, a leitura da obra foi dividida em três etapas: do início até a página 82, da página 83 a 138 e, por último, da página 139 até a 198. Também foi proposta aos alunos a elaboração de um portfólio, no qual estariam contidas todas as atividades desenvolvidas, conforme sugestão de Cosson (2009). Segundo o 
autor, a possibilidade de registrar as diversas atividades ao longo do processo permite a visualização do crescimento pela comparação dos resultados iniciais com os últimos, quer seja para o aluno, quer seja para a turma. Além disso, o portfólio promove um deslocamento: do polo no professor para o polo no aluno. À transmissão de conteúdos se contrapõem as habilidades e competências, e a resultados e produtos se sobrepõe o processo. Isso pressupõe que a formação do aluno se desprenda (somente) do que o professor ensina, desconsiderando o que o aluno aprende: acompanhar o processo de aprendizagem é dar a ele o tempo necessário para a apropriação dos conteúdos de ensino.

Então, na semana seguinte, o momento era o de checar o primeiro intervalo de leitura. Na escola 1, o critério utilizado para todos os intervalos de leitura foi o de elaboração de títulos para os capítulos lidos, tendo em vista que a obra não os nominava. A escola 2 decidiu por uma dinâmica de grupo. Para tanto, a turma foi dividida em dois grupos e algumas questões referentes aos capítulos lidos para aquele intervalo foram feitas. Ao final de cada intervalo de leitura, os pontos das equipes eram somados. $O$ grupo que mais pontuou na soma dos três intervalos de leitura foi premiado com um brinde ao final do processo. A equipe que ficou em segundo lugar também recebeu uma premiação pela participação.

Cosson sugere que os "Intervalos" sejam inseridos na terceira etapa da Sequência Expandida, a Leitura, a fim de que os alunos estabeleçam conexões da obra com textos menores, "[...] permitindo que se teçam aproximações breves entre o que já foi lido e o novo texto" (2009, p.63). Nesta proposta, optou-se por três intervalos. Assim, após a primeira averiguação de leitura, os alunos da escola 1 leram a crônica de Clarice Lispector, “O caso da caneta”, uma vez que o texto também aborda a relação entre dois irmãos que não conseguem viver harmoniosamente, nem mesmo com a intervenção direta da mãe que, através de suas atitudes, alimenta a rivalidade entre os irmãos. Após a leitura e discussão da crônica, trabalhou-se com o conceito do gênero, tendo em vista seus traços configuradores. A seguir, os alunos responderam algumas questões sobre o texto de Clarice Lispector, a fim de também estabelecer relação entre a convivência entre mãe e filhos na crônica e no romance. 
Os alunos da escola 2 assistiram a uma palestra proferida por um psicólogo, abordando alguns transtornos mentais recorrentes na sociedade moderna. Como atividade escrita, foram orientados a produzir um relatório da palestra apreciada. Para isso, foram instruídos sobre esse gênero textual. Os textos produzidos foram corrigidos pelos graduandos, que apontaram fragilidades encontradas nas produções. Então, foi solicitado aos alunos que realizassem a refacção textual.

É importante destacar que ao final de cada encontro foram realizadas reuniões entre os graduandos, professoras supervisoras e coordenadoras da Universidade, visando à realização de um "balanço" das atividades desenvolvidas e replanejamento das ações seguintes.

Considerando que Dois irmãos estabelece diálogo com personagens bíblicas Caim, Abel e Jó, sendo que Yaqub e Omar são comparados aos primeiros e Halim, ao último -, aos alunos foi apresentado o conceito de intertextualidade; também fotos, imagens e vídeos relacionados a personagens gêmeos - da história, da mitologia e de novelas. Ainda no segundo intervalo, depois da checagem de leitura, expôs-se o conceito do gênero textual dissertação subjetiva, a fim de que os alunos produzissem um texto comparando os conflitos vividos pelos personagens apresentados e os gêmeos da obra. Com o objetivo de reforçar o conceito de intertextualidade anteriormente apresentado, solicitou-se que os alunos apresentassem exemplos de intertextualidade, retirados de propagandas, revistas, música, etc. Foi um momento rico de aprendizagem e de descoberta dos recursos da linguagem. Vale ressaltar que, nas aulas subsequentes, os textos produzidos pelos alunos foram devolvidos e, posteriormente, reescritos, a fim de que se cumprissem alguns dos objetivos do subprojeto: a produção escrita e a análise linguística. ${ }^{2}$

$\mathrm{Na}$ escola 2, os bolsistas apresentaram o conceito de metalinguagem, presente na obra, evidenciando os intertextos do livro, bem como slides com exemplos de intertextos. Na sequência, buscando comprovar a intertextualidade entre as obras $A$ filha do escritor (2008), de Gustavo Bernardo, e O alienista (1979), de Machado de Assis, e

\footnotetext{
${ }^{2}$ Ação que foi executada em todas as produções escritas.
} 
ainda intencionando proporcionar compreensão mais abrangente sobre o enredo das histórias, os alunos assistiram ao vídeo baseado no conto machadiano, tendo em vista a presença marcante desse texto na construção do romance de Gustavo Bernardo. Como produção textual referente a esse intervalo, os alunos representaram, por meio de tiras, um trecho significativo dos capítulos lidos. Para tanto, receberam orientações sobre as especificidades do gênero textual tiras (de apenas três quadros). A atividade foi realizada em grupo, corrigida pelos graduandos e expostas para os grupos, em sala de aula.

Na última checagem de leitura, a escola 1 propôs um caça-palavras sobre o capítulo final da obra. Em seguida, como atividade do terceiro intervalo, fez-se a leitura e a discussão do conto de Machado de Assis, “O Espelho”, cujo objetivo foi debater questões ligadas à identidade, já que os personagens do romance, apesar de gêmeos, possuem personalidades completamente distintas. Enquanto Yaqub é introvertido, submisso e calado, Omar, o caçula, é desregrado e boêmio - disposto a pagar qualquer preço por uma "boa aventura" regada a mulheres, bebida e brigas. Em seguida, a turma foi dividida em cinco grupos para desenvolvimento de atividade que deveria ser realizada extraclasse. O grupo 1 ficou responsável por criar um monólogo a partir do momento em que Jacobina está em frente ao espelho; para tanto, foi exposto o conceito de monólogo; o grupo 2, deveria apresentar uma pesquisa a respeito das possíveis simbologias sobre o espelho; o grupo 3 deveria elaborar um vídeo em que cada aluno apresentaria sua identidade e a visão do outro sobre ele (eu e o outro); o grupo 4 deveria apresentar um diálogo entre Jacobina e Yaqub revelando a questão da alma exterior e interior de ambos os personagens, discussão presente no conto de Machado de Assis; e, finalmente, o grupo 5, deveria preparar questões para a realização de um jogo de perguntas referentes ao livro e ao conto; os que respondessem corretamente seriam premiados com doces.

$\mathrm{Na}$ escola 2, os alunos estouraram balões e neles encontravam a questão que deveriam responder. Essa forma lúdica para os questionamentos agradou bastante a turma. Ao término das questões, os pontos foram somados e a equipe que mais pontuou foi premiada com um brinde. Como já havíamos mencionado, a segunda colocação também recebeu premiação pela participação nas atividades. Neste dia, a leitura do último capítulo da obra $A$ filha do escritor foi realizada oralmente e, como síntese da 
atividade, trechos em que a metaficção se faz presente foram destacados. A atividade seguinte foi a leitura do poema "Ismália", de Alphonsus de Guimaraens. Os graduandos conduziram a análise do texto junto aos alunos que, na sequência, foram orientados a elaborar uma paródia do poema, privilegiando na composição feita por eles um personagem de destaque da obra A filha do escritor. Para a produção da paródia, houve orientação sobre o gênero textual. Após a correção, as produções realizadas pelos alunos foram afixadas na sala de aula. Como preparação para o próximo encontro, apresentamos o gênero textual entrevista. As graduandas realizaram um breve comentário sobre o gênero e os alunos manusearam revistas com entrevistas concedidas por escritores. Então, eles foram orientados a elaborar perguntas, que seriam selecionadas para que fossem feitas ao autor Gustavo Bernardo, em web conferência.

O próximo passo da sequência expandida é o da primeira interpretação. O objetivo dessa etapa “[...] é levar o aluno a traduzir a impressão geral do título, o impacto que ele teve sobre sua sensibilidade de leitor" (COSSON, 2009, p. 83). A fim de promover a prática literária de forma interdisciplinar e, tendo em vista que o romance de Milton Hatoum possui como pano de fundo o período que se estende do ciclo da borracha, passando pela segunda Guerra Mundial, pela modernização tardia do país em comparação aos demais, terminando com os reflexos da ditadura militar em Manaus, com o Golpe de 64, que desencadeou iniciativas estratégicas do governo que levariam à criação da Zona Franca de Manaus, a quarta etapa do trabalho contou com uma palestra de um professor de história. Ao término da fala do professor, foi solicitado que os alunos produzissem um relatório sobre as informações apresentadas por ele, que seria realizado extraclasse. Também foi pedido que os alunos escrevessem um texto de opinião relatando as impressões de leitura que cada um teve ao ler a obra; para tanto, o gênero artigo de opinião foi conceituado.

$\mathrm{Na}$ escola 2, os bolsistas apresentaram aos alunos as características de um resumo crítico e, a seguir, solicitou-se que elaborassem um texto sobre a obra $A$ filha do escritor, atendendo a esse gênero textual. Na semana seguinte, conforme contato e agendamento prévio com o escritor Gustavo Bernardo, os alunos fizeram perguntas ao 
autor, vendo-o e ouvindo-o em tempo real por meio de web conferência, via Skype, no laboratório de informática da escola 3 .

De acordo com a proposta de Cosson, o próximo passo da Sequência Expandida se dá pelas contextualizações. O pesquisador sugere a contextualização

[...] como o movimento de ler a obra dentro do seu contexto, ou melhor, que o contexto da obra é aquilo que ela traz consigo, que a torna inteligível para mim enquanto leitor. Dessa maneira, toda vez que leio um livro estou também lendo seu contexto, simplesmente porque texto e contexto se mesclam de tal maneira que resulta inútil estabelecer fronteiras entre eles. (...) A contextualização que propomos compreende o aprofundamento da leitura por meio de contextos que a obra traz consigo. (COSSON, 2009, p. 86)

Partindo do pressuposto de que o ensino da Literatura deve ser motivado pelo “[...] movimento contínuo de leitura, partindo do conhecido para o desconhecido, do simples para o complexo, do semelhante para o diferente, com o objetivo de ampliar e consolidar o repertório cultural do aluno" (COSSON, 2009, p. 48), é que se passou para a quinta etapa da Sequência Expandida, na qual foram selecionadas, também numa perspectiva interdisciplinar, as contextualizações presentificadoras, críticas e temáticas.

Na escola, 1 o grupo responsável pela contextualização presentificadora que, segundo Cosson (2009, p. 89), “[...] busca a correspondência da obra com o presente da leitura", foi orientado a pesquisar sobre os novos arranjos familiares; a pesquisa foi socializada para o restante da turma através de cartazes e dramatizações. O segundo grupo voltou-se para a contextualização crítica, o qual foi orientado a ler e depois apresentar para a turma os dois primeiros capítulos da dissertação de Mestrado de Selma R. Mascagna, intitulada Rastros de uma origem: espaço, tempo e subjetividade na obra Dois Irmãos, de Milton Hatoum, defendida na Universidade de São Paulo, em 2015. O capítulo 1, "Dois Irmãos na obra de Milton Hatoum", trata da relação entre Dois Irmãos e as demais obras do autor - Relato de um certo Oriente (1989), Cinzas do Norte (2005) e

\footnotetext{
${ }^{3}$ A Entrevista foi publicada na Revista Claraboia, de janeiro a junho de 2016, volume 5. Disponível em: <http://seer.uenp.edu.br/index.php/claraboia/article/view/759/pdf_63>.
} 
Órfãos do Eldorado (2008). Já o capítulo 2, "Espaço de Dois Irmãos", expõe a relação do espaço da casa com cada um dos personagens: Halim, Zana, Nael, Yaqub, Omar e Domingas. Depois, foram motivados a dramatizar o segundo capítulo do trabalho, uma vez que a "casa", no livro, é o centro dos conflitos familiares. Na contextualização temática, Cosson sugere que se avance sobre a temática despertada pela leitura. Desse modo, também sob orientação dos pibidianos, os alunos pesquisaram sobre os costumes, as tradições, a religião das famílias de origem libanesa, uma vez que o romance conta a história de uma família libanesa que migra para o Brasil, especificamente para Manaus. A pesquisa foi compartilhada com os demais alunos através da confecção de cartazes.

Também com o objetivo de ampliar o horizonte cultural dos alunos, traçando uma compreensão maior sobre a obra, internalizando o conteúdo de forma significativa, os alunos visitaram uma mesquita muçulmana, em Londrina, Paraná, onde tiveram a oportunidade de entrar em contato com a religião islâmica e, em consequência disso, com aspectos espinhosos a respeito da relação homem e mulher, por exemplo. Os alunos ainda tiveram a oportunidade de fazer perguntas ao sheik, as quais foram elaboradas previamente.

A escola 2 privilegiou as contextualizações: histórica, presentificadora e temática. Para o desenvolvimento das atividades, os alunos da turma foram divididos em três equipes e cada grupo ficou responsável por uma das contextualizações. Para cada uma das contextualizações utilizaram para pesquisa, a biblioteca e o laboratório de informática da escola. Na contextualização histórica, buscaram informações sobre arquitetura, costumes, trajes, comunicação, meios de comunicação, meios de transporte, linguagem, direitos da mulher, etc.; contrastando os dois momentos citados no livro $A$ filha do escritor, o final do século XIX e a contemporaneidade. Na presentificadora, discutiu-se sobre as implicações de ter na família um ente com distúrbios mentais. Foram orientados a destacar as maiores dificuldades, preconceitos enfrentados, cuidados, mudanças, superação, etc. Coube a eles pesquisar casos de famosos na internet, como também de conhecidos da comunidade em que vivem. Na contextualização temática, os alunos procuraram representar como a relação entre médico e paciente é vista na sociedade atual, além de apresentar casos em que a relação ética entre médico e 
paciente é violada. Esta atividade justificou-se devido à suposta relação que o personagem médico da obra procura manter com uma outra personagem, no caso, sua paciente. As atividades das três contextualizações foram iniciadas em sala para que depois dos orientados, os alunos pudessem sequenciá-las na biblioteca, laboratório de informática e também em segmentos fora do âmbito escolar. Os resultados obtidos pelos grupos foram apresentados em forma de "seminário", momento em que os alunos exibiram cartazes e fizeram explicações orais sobre as pesquisas realizadas.

De acordo com Cosson, “[...] ao contrário da primeira, que busca uma apreensão global da obra, a segunda interpretação tem por objetivo a leitura aprofundada de um de seus aspectos" (COSSON, 2009, p. 92). Assim, na escola 1, foi realizada uma entrevista com três grupos de gêmeos, estudantes da própria instituição, sendo dois grupos de meninas e um de menino. A eles foram feitas perguntas sobre como é ser e/ou ter irmão gêmeo, as quais foram elaboradas previamente sob a supervisão dos pibidianos. Vale lembrar que esta atividade foi elaborada devido à obra Dois Irmãos contar a história dos irmãos gêmeos Yaqub e Omar. Ao término da aula, o grupo se reuniu em uma sala do colégio para uma entrevista com Milton Hatoum via telefone, anteriormente agendada. O autor respondeu prontamente e gentilmente a todas as perguntas elaboradas pelos alunos e pelos bolsistas a respeito da gênese de Dois irmãos e de suas demais obras, influências literárias, processo de criação literária, funções da literatura, bem como sobre a importância da formação de leitores, foco principal deste subprojeto ${ }^{4}$.

Na escola 2, optou-se por abordar de modo mais profundo a questão de transtornos mentais. Dividimos os alunos da turma em sete grupos e cada equipe ficou responsável por pesquisar sobre um transtorno mental, indicado pela bolsista designada para orientar o grupo. A partir dos estudos realizados, os integrantes das equipes representaram, por meio de desenho em cartolina, os transtornos pesquisados. A socialização dos resultados foi feita no grande grupo, momento em que cada equipe apresentou seu desenho e os integrantes teceram comentários sobre os resultados obtidos na investigação.

\footnotetext{
${ }^{4}$ A entrevista foi publicada na Revista Claraboia, volume 5, janeiro a junho de 2016. Disponível em: <http://seer.uenp.edu.br/index.php/claraboia/article/view/762/pdf_67>.
} 
Na última etapa que, segundo Cosson (2009), é o movimento que ultrapassa o limite da obra e busca possibilidades de diálogo entre textos que a precederam, que lhes são contemporâneos ou posteriores, o que também requer repertório de leitura dos envolvidos, foi sugerida a leitura do romance Esaú e Jacó, de Machado de Assis, na escola 1. A seleção desta obra deu-se pela temática: ambas tratam de conflito entre irmãos gêmeos. Para a escola 2, apresentamos aos alunos a obra O alienista (1979), de Machado de Assis, indicando-a para leitura.

Importante destacar que a alternância entre atividades de leitura e escrita é uma das três perspectivas metodológicas propostas por Cosson (2009). Denominada de técnica da oficina, ela parte do princípio de que para cada atividade de leitura é preciso uma atividade de escrita ou registro. A segunda metodologia é a técnica do andaime, que transfere para o aluno a edificação do conhecimento, a qual, por sua vez, vincula-se à terceira perspectiva, a do portfólio, já discutida anteriormente.

\section{Considerações finais}

Tendo em vista os percalços que envolvem o processo de educação literária nas escolas da rede pública, vimos no projeto realizado um excelente meio para que o letramento literário se configure com sucesso. O uso de estratégias bem amparadas teoricamente contribuiu para a eficácia do trabalho desenvolvido. Sabemos que os desafios são muitos e que, mesmo tendo um profissional capacitado, esbarramos em outros aspectos de ordem social, política e econômica que interferem nas práticas escolares e no sucesso educacional. No entanto, consideramos, também, que a formação profissional é ponto sine qua non para elevar a qualidade do ensino. Sem um profissional consciente de sua função e instrumentalizado para desenvolver seus objetos e metas, o ensino não se efetiva.

Ressaltamos a importância do PIBID que, além de inserir os licenciandos no cotidiano das escolas da rede pública de educação, eleva a qualidade da formação inicial dos professores nos cursos de licenciatura, o que deve implicar na melhoria da qualidade da educação básica pública brasileira e na valorização do magistério. Além dos aspectos já 
mencionados em relação às contribuições do PIBID para a formação do licenciando, destacamos a oportunidade para formação continuada de professores da rede pública, que, muitas vezes, reproduzem práticas cristalizadas, estratégias repetitivas, atreladas à formação inicial, por desconhecerem teorias atuais, que podem contribuir na aprendizagem do aluno.

Entendemos, por meio das experiências de sucesso da edição do PIBID em 2015, que é possível desenvolver um trabalho significativo com o texto literário na Educação Básica. O caminho, neste caso, indica ser necessário (ainda que reconheçamos a complexidade a ele inerente) melhor preparo do profissional em formação para a atuação na docência, trabalho com o texto literário em sala de aula, de acordo com estudos e planejamentos, e formação continuada para o professor da rede, sob a coordenação dos professores da IES.

\section{Referências}

ANDRADE, Carlos Drummond de. Boitempo I. Rio de Janeiro: Record, 1989.

ASSIS, Machado de. O Alienista. In: Obra Completa. Vol. II, Conto e Teatro. Organizada por Afrânio Coutinho, $4^{a}$ edição, ilustrada. Rio de Janeiro, Editora Nova Aguilar, 1979. p. 253-28.

BERNARDO. Gustavo. A filha do escritor. Rio de Janeiro: Agir, 2008.

CANDIDO, Antonio. A literatura e a formação do homem. Ciência e Cultura, São Paulo, v. 4, n. 9, p. 803-809, set., 1972.

COSSON, Rildo. Letramento literário: teoria e prática. São Paulo: Contexto, 2009.

ELIAS, leda Maria Sorgi Pinhaz. Entrevista com Gustavo Bernardo. Claraboia, Jacarezinho, v.5, p. 129-135, jan./jun., 2016. Disponível em:

<http://seer.uenp.edu.br/index.php/claraboia/article/view/759/pdf_63>. Acesso em 25 jul 2016.

FELICIANO, Danivia Cassiano; BARBOSA, Letícia. Entrevista com Milton Hatoum.

Claraboia, Jacarezinho, v.5, p. 129-135, jan./jun., 2016. Disponível em: 
<http://seer.uenp.edu.br/index.php/claraboia/article/view/762/pdf_67>. Acesso em 25 jul 2016.

HATOUM, Milton. Cinzas do Norte. São Paulo: Companhia das Letras, 2005.

HATOUM, Milton. Dois irmãos. São Paulo: Objetiva, 2000.

HATOUM, Milton. Órfãos do Eldorado. São Paulo: Companhia das Letras, 2008.

HATOUM, Milton. Relato de um certo oriente. São Paulo: Companhia das Letras, 1989.

PARANÁ. Secretaria de Estado da Educação. Diretrizes curriculares de língua portuguesa para a educação básica. Curitiba: SEED, 2008.

SOARES, Magda. A escolarização da literatura infantil e juvenil. In: EVANGELISTA, Aracy Alves Martins et al. (Orgs.). A escolarização da leitura literária: o jogo do livro infantil e juvenil. Belo Horizonte: Autêntica, 2001. p. 17-48.

ZILBERMAN, Regina. Fim do livro, fim dos leitores? São Paulo: Editora Senac São Paulo, 2001.

Recebido em: 29/07/2016 Aprovado em: 31/10/2017

Universidade do Estado de Santa Catarina - UDESC

Centro de Ciências Humanas e da Educação - FAED

Revista PerCursos

Volume 18 - Número 38 - Ano 2017 revistapercursos@gmail.com 